\title{
NQR and Phase Transitions in Hexachlorocyclopropane Crystal*
}

\author{
Masahiko Suhara \\ Department of Chemistry, Faculty of Science, Kanazawa University, \\ 1-1 Maru-no-uchi, Kanazawa 920, Japan \\ Koichi Mano \\ Department of Applied Chemistry, Faculty of Engineering, Osaka City University, \\ Sugimoto, Sumiyoshi-ku, Osaka 558, Japan \\ Z. Naturforsch. 45a, 339-342 (1990); received August 23, 1989 \\ ${ }^{35} \mathrm{Cl} \mathrm{NQR}$ and DSC studies on phase transitions in hexachlorocyclopropane ( $\left.\mathrm{HCCP}\right), \mathrm{C}_{3} \mathrm{Cl}_{6}$, are \\ reported. It is found that HCCP has three solid phases: A high temperature disordered phase \\ (Phase I) above $301 \mathrm{~K}$ (no NQR spectrum was observed); a metastable phase (Phase II), which \\ exhibited 6 NQR lines from 77 to $270 \mathrm{~K}$; a low temperature phase (Phase III) in which a 24-multiplet \\ of ${ }^{35} \mathrm{Cl} \mathrm{NQR}$ lines at $77 \mathrm{~K}$, the most complex multiplet spectrum ever reported was observed. \\ DSC measurement shows a $\lambda$-type transition at $301 \mathrm{~K}$ and a broad transition of very slow rate \\ at $285 \mathrm{~K}$. The structure and mechanism of phase transitions in HCCP crystal are discussed. \\ Key words: Nuclear quadrupole resonance, Phase transition, Crystal structure, Differential scan- \\ ning calorimetry, Order-disorder transition.
}

\section{Introduction}

Structural phase transitions of crystals formed by nearly spherical molecules are an interesting field in solid state physics [1]. For example, methane [2] and adamantane [3] form a face-centered cubic lattice which is usually a disordered phase. With decreasing temperature, this lattice transforms to orientationally ordered structures. NQR is very usefull to investigate the crystal structure and phase transition when multiplet lines are originated from the crystallographically inequivalent atoms which belong to chemically equivalent sites in a free molecule. The most striking example so far reported is carbon tetrachloride, which shows a 16 -line ${ }^{35} \mathrm{Cl} \mathrm{NQR}$ spectrum [4]. This comes from the formation of a large unit cell with $32 \mathrm{CCl}_{4}$ molecules. In this paper, we report a very complex multiplet-pattern of an NQR spectrum and several phase transitions found in solid hexachlorocyclopropane (HCCP). The resemblance of the polymorphism in $\mathrm{CCl}_{4}$ to that in HCCP is also discussed.

\footnotetext{
* Presented at the Xth International Symposium on Nuclear Quadrupole Resonance Spectroscopy, Takayama, Japan, August 22-26, 1989.

Reprint requests to Prof. M. Suhara, Department of Chemistry, Faculty of Science, Kanazawa University, 1-1 Maru-nouchi, Kanazawa 920, Japan.
}

\section{Experimental}

NQR signals were detected by means of a Kushida type regenerative oscillator detector with a second harmonics detection to avoid the side-band interference in a superregenerative detector. The resonance frequency was measured by means of pip marks at $10 \mathrm{kHz}$ intervals on a chart generated by a frequency counter. Details of the spectrometer have been reported elsewhere [5].

A differential scanning calorimeter (DSC), Rigaku DSC 8058, was employed for thermal analysis.

\section{Results}

\section{DSC Measurements}

The phase transitions of solid HCCP at atmospheric pressure were observed by measuring DSC curves as shown in Figure 1. Run a shows the heating curve exhibiting a $\lambda$-type transition at $301 \mathrm{~K}$. The high and low temperature phases are denoted by I and III, respectively. Run b, the second run, exhibits an anomalous DSC curve which is superimposed with a $\lambda$-type transition peak and a broad one. The transition corresponding to the broad peak is very slow and could be observed once at the second run in one sam- 


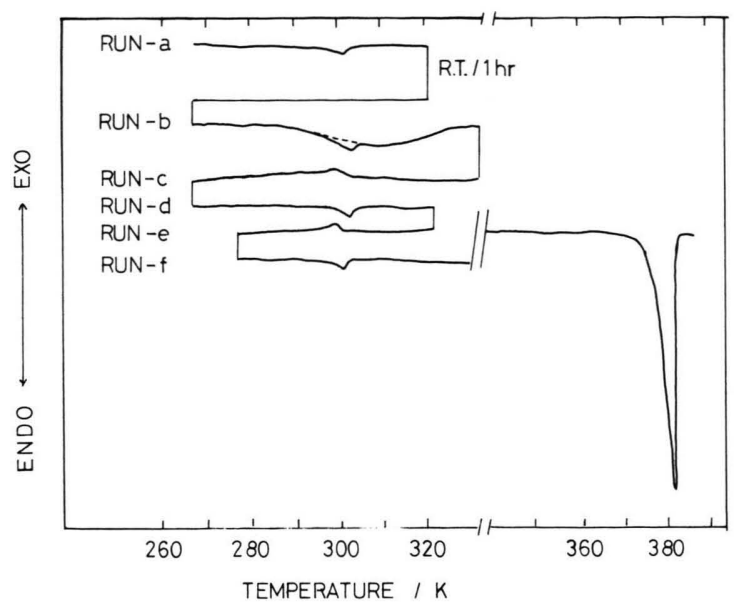

Fig. 1. DSC curves in hexachlorocyclopropane.
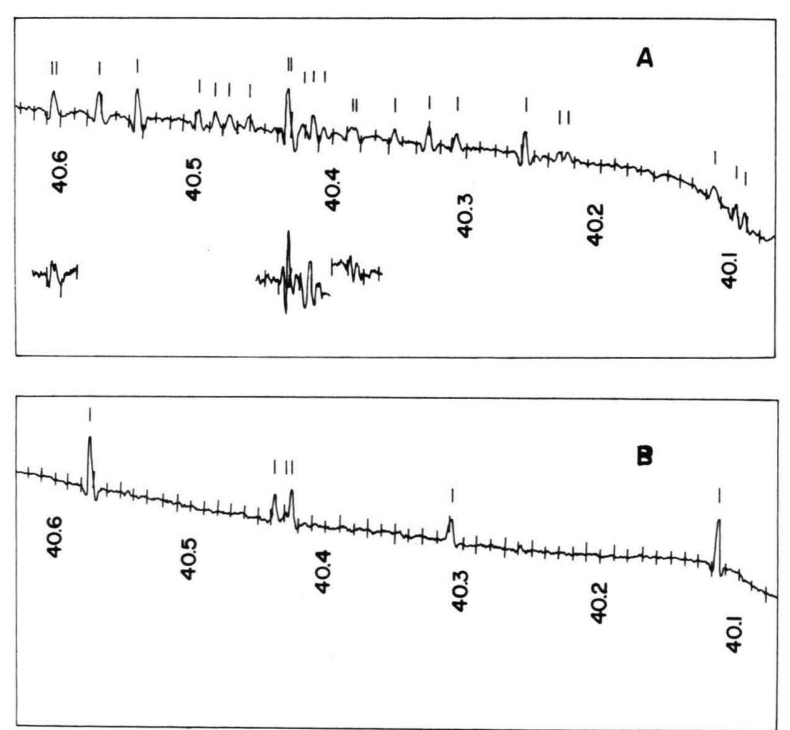

Fig. $2 .{ }^{35} \mathrm{Cl}$ NQR spectrum in (A) Phase III and (B) Phase II of hexachlorocyclopropane at $77 \mathrm{~K}$, together with frequency marks of $10 \mathrm{kHz}$ intervals and frequency in $\mathrm{MHz}$.

ple as seen in Figure 1. Afterward, only the $\lambda$-type transition was observed reversively. This new phase is denoted by Phase II. The transition point $\left(T_{\mathrm{c}}\right)$ from II to $\mathrm{I}$ is $285 \mathrm{~K}$. The melting point $\left(T_{\mathrm{m}}\right)$ is $376 \mathrm{~K}$. The enthalpies of transition in run $\mathrm{a}$ and run $\mathrm{b}$ are 0.21 and $1.26 \mathrm{~J} \mathrm{~mol}^{-1}$, respectively. This leads to the value of $1.05 \mathrm{~J} \mathrm{~mol}^{-1}$ for the slow transition. The enthalpy and entropy changes at $T_{\mathrm{m}}$ are $18.6 \mathrm{~kJ} \mathrm{~mol}^{-1}$ and $49 \mathrm{~J} \mathrm{~mol}^{-1} \mathrm{~K}^{-1}$, respectively.

\section{$N Q R$ Measurement}

The sample crystallized from n-propane shows no ${ }^{35} \mathrm{Cl}$ signal in I. At $77 \mathrm{~K}$, a very complicated multipletspectrum consisting of 24 lines was observed, as shown in Figure 2 A. The sample, kept at $343 \mathrm{~K}$ over a period of several weeks, showed the same spectrum at $77 \mathrm{~K}$. The sample crystallized from a melt also exhibited the same pattern at $77 \mathrm{~K}$. This 24-lines spectrum is one of the most complex multiplet NQR spectra ever reported. Repeating the heating and/or cooling of the sample, the spectrum pattern turned to a very simple spectrum of 6 lines, as shown in Figure $2 \mathrm{~B}$. After the sample of II was kept at $253 \mathrm{~K}$ or at room temperatur for a long time, a mixed spectral pattern of two modifications, II and III, was observed, and finally no resonance for II could be observed, no matter how the temperature of specimen was varied. The rate of transition between II and III was quite small and equilibrium was not reached in a reasonable period of time. So, the transition temperature could not be determined from the NQR measurement. The temperature dependence of ${ }^{35} \mathrm{Cl} \mathrm{NQR}$ frequencies in II and III is shown in Figs. $3 \mathrm{~A}$ and $3 \mathrm{~B}$, respectively. Most of the resonance lines in III faded out considerably below $T_{\mathrm{c}}=301 \mathrm{~K}$, whereas in II the resonance was detected at $270 \mathrm{~K}$, which was slightly below $T_{\mathrm{c}}=$ $285 \mathrm{~K}$. The disappearance of the resonance signal can be attributed to the orientational disordering of molecules due to librational motions in the crystal. The resonance lines in III disapper at a lower temperature than those in II. Such a fade-out has also been observed in the case of chloral hydrate crystal [6].

\section{Discussion}

From the DSC and NQR observations, we confirmed three phases: a high temperature phase (I), a metastable one (II), and a low temperature one (III), as shown in Figure 4. The HCCP and $\mathrm{CCl}_{4}$ molecules are nearly spherical and all of the chlorine atoms in a molecule are chemically equivalent. The crystal structure and mechanism of phase transition in $\mathrm{HCCP}$ are expected to be similar to those in $\mathrm{CCl}_{4}$. The phase diagram for $\mathrm{CCl}_{4}$ was determined by Bridgman [7] and Trapeniers [8], who obtained at least three different solid phases at temperatures of 233 to $458 \mathrm{~K}$ and pressures of 0 to $10^{4} \mathrm{~kg} \mathrm{~cm}^{-2}$. The crystal structure of II was determined by Rudman and Post [9] and Weir et al. [10], and that of III by Piermarini and Braun 

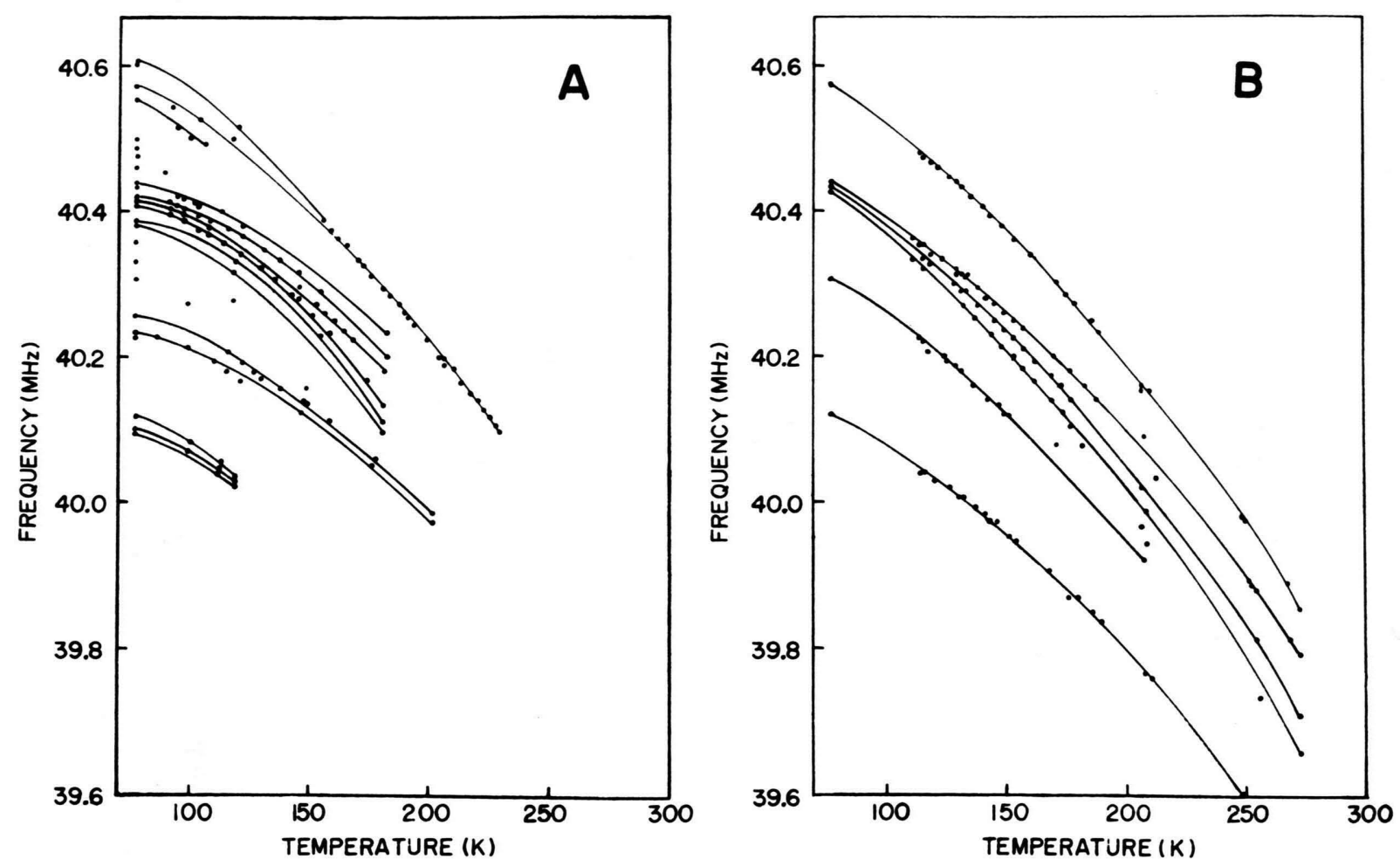

Fig. 3. Temperature dependence of ${ }^{35} \mathrm{Cl}$ NQR frequencies in (A) Phase III and (B) Phase II of hexachlorocyclopropopane

\begin{tabular}{|c|c|c|}
\hline PHASE III & \multirow{2}{*}{ PHASE I } & \multirow{2}{*}{$L$} \\
\hline $\begin{array}{c}\text { PHASE II } \\
\text { metastable }\end{array}$ & & \\
\hline \multicolumn{3}{|c|}{$\begin{array}{c}\text { PHASE I } \\
\text { metastable }\end{array}$} \\
\hline 260 & & 400 \\
\hline & $\mathrm{E} / \mathrm{K}$ & \\
\hline
\end{tabular}

Fig. 4. The phases of hexachlorocyclopropane.

[11]. The structure of II obtained at 123 to $248 \mathrm{~K}$ and atmospheric pressure is ordered pseudo-cubic monoclinic with a very large cell dimension containing 32 molecules. The structure of III is monoclinic with 4 molecules per unit cell at room temperature and a pressure of $10^{4} \mathrm{~kg} \mathrm{~cm}^{-2}$ [11]. Crystal data for HCCP show a pseudo-body-centered monoclinic form containig 4 molecules [12], which has been determined at low temperature and atmospheric pressure. We can compare $\mathrm{HCCP}$ and $\mathrm{CCl}_{4}$. The similarity of the crys-
Table 1. Crystal and NQR data for $\mathrm{CCl}_{4}$ and $\mathrm{HCCP}$.

\begin{tabular}{|c|c|c|}
\hline \multirow[t]{2}{*}{ Compounds } & \multicolumn{2}{|c|}{ Ordered phases } \\
\hline & Phase II & Phase III \\
\hline $\mathrm{CCl}_{4}$ & $\begin{array}{l}0 \mathrm{~kg} \mathrm{~cm}^{-2} \\
T<225.5 \mathrm{~K} \\
Z=32 \\
N_{\mathrm{NQR}}=16\end{array}$ & $\begin{array}{l}10^{4} \mathrm{~kg} \mathrm{~cm}^{-2} \\
T=\text { room temp. } \\
Z=4 \\
N_{\text {X-ray }}=4\end{array}$ \\
\hline & Phase III & Phase II \\
\hline $\begin{array}{l}\text { cyclo- } \mathrm{C}_{3} \mathrm{Cl}_{6} \\
\text { (HCCP) }\end{array}$ & $\begin{array}{l}0 \mathrm{~kg} \mathrm{~cm}^{-2} \\
T<301 \mathrm{~K} \\
Z=32 \\
N_{\mathrm{NQR}}=24\end{array}$ & $\begin{array}{l}0 \mathrm{~kg} \mathrm{~cm}^{-2} \\
T<285 \mathrm{~K} \\
Z=4 \\
N_{\mathrm{NQR}}=6\end{array}$ \\
\hline
\end{tabular}

$Z$ and $N$ denote the numbers of molecules and inequivalent chlorine sites in a unit cell, respectively.

tal data and the results of NQR measurements are shown in Table 1. The values of $16 / 24$ and $4 / 6$, which are the ratios of the number of equivalent chlorine sites in each pair of phases, are equal to the ratio of the number of chlorine atoms between the two molecules. 
This suggests that the structure and polymorphism observed in HCCP crystal are the same as those in $\mathrm{CCl}_{4}$. The transition mechanism is believed to give a

[1] T. H. K. Barron and C. Domb, Proc. Roy. Soc. A 227 , 447 (1965). - T. Kihara, J. Phys. Soc. Japan 7, 348 (1952). - L. Jansen and E. Lombardi, Disc. Faraday Soc. 20, 35 (1952).

[2] A. Schallamach, Proc. Roy. Soc. A 171, 589 (1939). J. Herczec and R. E. Stoner, J. Chem. Phys. 54, 2284 (1971).

[3] C. E. Nordman and D. L. Schmitkons, Acta Cryst. 18, 764 (1965).

[4] R. Livingston, J. Phys. Chem. 57, 496 (1953). - H. Okuma, N. Nakamura, and H. Chihara, unpublished work refered in: T. Atake and H. Chihara, J. Chem. Thermodyn. 3, 51 (1971). - S. Murata, K. Fujita and M. Suhara, Chem. Lett. 1067 (1973).

[5] M. Suhara, Sci. Rep. Kanazawa Univ. 17, 7 (1972). slight change in the packing of molecules whose centers of mass are unaffected by the transition, as suggested for solid $\mathrm{CCl}_{4}[13]$.

[6] D. Biedenkapp and Al. Weiss, Z. Naturforsch. 22 a, 1124 (1967)

[7] P. W. Bridgman, Phys. Rev. 3, 153 (1914).

[8] N. T. Trappeniers, refered in: J. Timmermans, J. Phys. Chem. Solid 18, 1 (1961).

[9] R. Rudman and B. Post, Science 154, 1009 (1966).

[10] C. E. Weir, G. J. Piermarini, and S. Block, J. Chem. Phys. 50, 2089 (1969).

[11] G. J. Piermarini and A. B. Braun, J. Chem. Phys. 58, 1974 (1973).

[12] T. Takano, T. Chiba, Y. Sasada, M. Kakudo, S. Nozakura, and S. Murahashi, Bull. Chem. Soc. Japan 38, 157 (1965) together with the private communications.

[13] B. M. Mogilevskii and V. G. Surin, Sov. Phys. Solid State 13, 234 (1971). 